\title{
TIME COURSE OF THE INDUCTION OF ARYL HYDROCARBON HYDROXYLASE IN RAT LIVER NUCLEI AND MICROSOMES BY PHENOBARBITAL, 3-METHYLCHOLANTHRENE, 2,3,7,8-TETRACHLORO- DIBENZO-P-DIOXIN, DIELDRIN AND OTHER INDUCERS
}

\author{
Andreas Viviani, Werner K. Lutz and Christian Schlatter \\ Institute of Toxicology, Federal Institute of Technology and University of Zurich, \\ CH-8603 Schwerzenbach, Switzerland
}

(Received 20 September 1977; accepted 5 December 1977)

\begin{abstract}
Aryl hydrocarbon hydroxylase (AHH) has been measured in male rat liver nuclei and microsomes after treatment of adult animals with various inducers for up to 14 days. After daily i.p. injections of 3-methylcholanthrene $(\mathrm{MC}, 20 \mathrm{mg} / \mathrm{kg}$ ) the nuclear activity increased to a maximum of 600 per cent of the control activity after 4 days whereas the microsomal activity was 400 per cent of control at the same date. After 12 days, both activities equilibrated at 400 per cent. A similar time course was found after a single i.p. injection of 2,3,7,8-tetrachloro-dibenzo-p-dioxin (TCDD, 0.01 $\mathrm{mg} / \mathrm{kg}$ ) with an induction to 500 and 300 per cent for nuclei and microsomes, respectively, after 2 days, and to 400 per cent for both after 12 days. Phenobarbital (PB) was given continuously in the drinking water $(1 \mathrm{~g} / \mathrm{l})$ and induced the microsomal activity to 200 per cent after 8 days and 170 per cent after 14 days. The nuclear activity was only slightly induced to a constant level of 130 per cent between day 8 and 14. Dieldrin did not significantly increase the microsomal activity after daily i.p. injections $(20 \mathrm{mg} / \mathrm{kg})$, but the nuclear activity raised to 200 per cent after 3 days and levelled down to control values after 12 days. Other inducers tested were benz $[a]$ anthracene $(B A)$, hexachlorobenzene (HCB) and 1,1,1-trichloro-2,2-bis(p-chlorophenyl)ethane (DDT). The induction pattern with BA was similar to that of MC, a model compound for the group of cytochrome P448 inducers. The induction by HCB and DDT resembled that by PB, a typical cytochrome P450 inducer.
\end{abstract}

The aryl hydrocarbon hydroxylase (benzo[a]pyrene hydroxylase, AHH, ${ }^{*}$ E.C. 1.14.14.2) is an inducible, membrane-bound enzyme belonging to the group of mixed function oxygenases mediated by the $\mathrm{P} 450$ cytochromes [1-3]. AHH holds a central place in the metabolism of foreign compounds and in the activation of chemical carcinogens to electrophilic metabolites, especially of PAH [4-7]. In mammalian liver, $\mathrm{AHH}$ is found in the ER, but also, with much less activity, in the outer membrane of the nucleus, and the binding of PAH to protein and DNA can be catalyzed by microsomes as well as by isolated nuclei [8-19]. AHH can be induced by a variety of substances and it has been established that the extent of binding of PAH to protein and DNA in vitro is correlated to the induction of $A H H$ in microsomes, nuclei or both $[14,15,17,19]$. It has also been shown that the carcinogenic potency of different PAH is correlated with the extent of binding to DNA $[20,21]$. The tumour incidence from exposure to $\mathrm{PAH}$ is affected to some extent by other

* Abbreviations-AHH, aryl hydrocarbon hydroxylase: BA, benz[ $a$ ]anthracene; BP, benzo[ $a$ ]pyrene; DDT, 1,1,1trichloro-2,2-bis(p-chlorophenyl)ethane; HCB, hexachlorobenzene: MC, 3-methylcholanthrene; PB, phenobarbital; TCDD, 2,3,7,8-tetrachloro-dibenzo-p-dioxin; PAH, polycyclic aromatic hydrocarbons; ER, endoplasmic reticulum. compounds and there is indication that this is due to an alteration of the PAH metabolism, particularly to changes in AHH activity [3, 22-24]. An induction could have a direct influence on the carcinogenic action of a PAH by altering the extent of its binding to the nucleic acids. It was suggested that the nuclear AHH might be especially important in this process due to its proximity to the DNA $[12,15]$.

The extent of short-term induction of AHH activity was found to be different in microsomes and nuclei and dependent on the inducer used $[9,14,17]$ and the hypothesis was considered that the two compartments are under separate control. Due to the fact that the AHH activity found in the nucleus is much lower than the one found in the microsomal fraction much work was performed on microsomes but very little on the nuclear AHH, of which only short term induction experiments have so far been published. No data are available on the induction after prolonged administration of a certain inducer although this knowledge is necessary for a discussion of the regulatory aspects of the induction as well as for an evaluation of the effects of chronic exposure to inducing drugs. Here, we report the time course of the $\mathrm{AHH}$ induction in rat fiver nuclei and microsomes after treatment with different inducers for up to 14 days. The study reveals different induction levels of the two sites in the first few days 
of the treatment and an equilibration to an equal induction level after prolonged administration.

\section{EXPERIMENTAI}

Chemicals. MC. BA, BP, dieldrin, DDT and HCB were obtained from Fluka AG, Buchs, Switzerland. BP was purified by column chromatography in hexane on silicagel for the AHH assay. Dieldrin, HCB and DDT were purified prior to use by recrystallization. TCDD was generously supplied by Givaudan SA. Dübendorf, Switzerland. Sodium phenobarbital was obtained from the Kantonsapotheke Zürich. NADP, glucose-6-phosphate and glucose-6-phosphate dehydrogenase (E.C. 1.1.1.49, from L. mesenteroides) from Boehringer, bovine serum albumin (fraction V) from Sigma. 3-hydroxyBP was a gift from the NIH. The other reagents used were of the purest grade commercially available.

Animals. Male rats (SIV 50, Sprague-Dawley derived. $180-250 \mathrm{~g}$ ) were obtained from the Kantonales Tierspital, Zürich. Switzerland and were housed two per cage on sawdust in clear plastic cages. Nafag laboratory chow (Nafag AG, Gossau, Switzerland) and tap water was provided ad libitum.

Enzyme induction. The dosage was selected as to achieve a maximal induction without producing toxic side effects as judged by normal gain of weight PB was given in the drinking water as a solution of $1 \mathrm{~g} / \mathrm{l}$ sodium phenobarbital and was freshly prepared every day. MC (20 mg/kg), BA $(20 \mathrm{mg} / \mathrm{kg})$, dieldrin $120 \mathrm{mg} / \mathrm{kg})$ and DDT $(30 \mathrm{mg} / \mathrm{kg})$ were dissolved in corn oil and $2 \mathrm{ml} / \mathrm{kg}$ were injected intraperitoneally. HCB $(100 \mathrm{mg} / \mathrm{kg})$ had to be dissolved in hot oil $\left(60^{\circ}\right)$ and was injected as a milky suspension after fast cooling. TCDD was dissolved in toluene 10.25 $\mathrm{mg} / \mathrm{ml}$ ). $0.4 \mathrm{ml}$ of this solution was given into $10 \mathrm{ml}$ of corn oil and the toluene was evaporated by bubbling a stream of nitrogen through the solution during $4 \mathrm{hr}$ at room temperature. $1 \mathrm{ml} / \mathrm{kg}$ of this solution ( $10 \mu \mathrm{g}$ TCDD $/ \mathrm{kg}$ ) was injected intraperitoneally. All injections were made at $0800 \mathrm{hr}$. Control animals received equivalent volumes of corn oil. There was no significant difference between the AHH values from untreated or oil-treated animals.

Cell fractionation. All manipulations and centrifugations were performed at $3-5^{\circ}$. At the day of sacrifice, the animals weighed between 280 and 320 g. They were killed by stunning and cervical dislocation, the liver was promptly excised and washed twice in ice-cold $0.25 \mathrm{M}$ sucrose in $50 \mathrm{mM}$ tris $-\mathrm{HCl}$ pH 7.5, $2.5 \mathrm{mM} \mathrm{KCl}, 5 \mathrm{mM} \mathrm{MgCl}_{2}$ (= sucroseTKM). $4 \mathrm{~g}$ of liver from the big lobe were homogenized in $12 \mathrm{ml}$ of $0.25 \mathrm{M}$ sucrose-TKM in a loose-fitting Potter-Elvehjem homogenizer with a tefion pestle of $0.2 \mathrm{~mm}$ clearance with 10 up-anddown strokes at $500 \mathrm{rpm}$. The homogenate was passed through a 10()-mesh nylon cloth and centrifuged in a $17 \mathrm{ml}$ transparent plastic tube at $2000 \mathrm{~g}$ for $20 \mathrm{~min}$ in a Sorvall RC-5B centrifuge.

Nuclei. The pellet was used for the preparation of nuclei according to the method of Berezney et al. [25] with considerable modifications: After washing the pellet twice with $0.25 \mathrm{M}$ sucrose-TKM and centrifugation at $1000 \mathrm{~g}$ for $5 \mathrm{~min}$. the crude preparation was resuspended in $15 \mathrm{ml}$ of $2.2 \mathrm{M}$ sucrose-
TKM by vortex mixing. $2 \mathrm{ml}$ of $2.3 \mathrm{M}$ sucrose-TKM were underlayed with a long Pasteur pipette and the tube was centrifuged for $20 \mathrm{~min}$ at $23,000 \mathrm{rpm}$ $(80,000 \mathrm{~g})$ in a $6 \times 17 \mathrm{ml}$ Sorvall AH-627 swinging bucket rotor. The supernatant was decanted, the inside of the tube wiped with sof tissues, the tube was gently rinsed with $2 \mathrm{ml}$ of $0.25 \mathrm{M}$ sucrose-TKM without resuspending the pellet and wiped again. 5 $\mathrm{ml} 0.25 \mathrm{M}$ sucrose-TKM were added, the pellet was detached from the bottom with a glass rid and carefully resuspended. After mixing with $10 \mathrm{ml}$ of $2.2 \mathrm{M}$ sucrose-TKM $2 \mathrm{ml}$ of $2.3 \mathrm{M}$ sucrose-TKM were underlayed and the tube was centrifuged for $20 \mathrm{~min}$ at $80,000 \mathrm{~g}$. The supernatant was decanted, the tube cleaned and the pellet taken up in $2 \mathrm{ml}$ of $1.0 \mathrm{M}$ sucrose-TKM as described above. The tube was then filled with $1.0 \mathrm{M}$ sucrose-TKM and centrifuged for $5 \mathrm{~min}$ at $2000 \mathrm{~g}$. The supernatant was decanted and the pellet was resuspended in $2 \mathrm{ml}$ of $0.25 \mathrm{M}$ sucrose-TKM and centrifuged for $5 \mathrm{~min}$ at $1000 \mathrm{~g}$ The purified nuclei were resuspended in $2 \mathrm{ml}$ of the assay buffer (see below).

Microsomes. The supernatant from the first centrifugation step was used for the preparation of microsomes with the $\mathrm{Ca}^{2+}$-precipitation method [26]: The supernatant was centrifuged for $10 \mathrm{~min}$ at $12,000 \mathrm{~g}$. The supernatant was carefully pipetted off and an aliquot was rapidly mixed with five volumes of a solution containing $10 \mathrm{mM}$ sucrose. $9.6 \mathrm{mM}$ $\mathrm{CaCl}_{2}$. The tube was allowed to stand in ice for 10 min and centrifuged for $8 \mathrm{~min}$ at $1000 \mathrm{~g}$ at $0^{\circ}$. The pellet was resuspended in the original volume of the aliquot with $0.25 \mathrm{M}$ sucrose-TKM and the same step was repeated. The final pellet was resuspended in $2 \mathrm{ml}$ of the assay buffer (see below).

AHH assay. Reactions were carried out in $25 \mathrm{ml}$ wide neck conical flasks at $37^{\circ}$. All reagents except BP were prepared in $50 \mathrm{mM}$ tris $-\mathrm{HCl}$ pH $7.5 .3 \mathrm{mM}$ $\mathrm{MgCl}_{2}$, I $\mathrm{mM} \mathrm{KCl}$ (=assay buffer). To one flask were added: $800 \mu \mathrm{l}$ of the assay buffer: $100 \mu \mathrm{l}$ of a cofactor mixture containing $57 \mathrm{mg} / \mathrm{ml}$ glucose- 6 phosphate, $32 \mathrm{mg} / \mathrm{ml}$ NADP and 40 units $/ \mathrm{ml}$ (40) $\mu \mathrm{g} / \mathrm{ml}$ ) glucose-6-phosphate dehydrogenase: 50 () $\mu$ l of $40 \mathrm{mg} / \mathrm{ml}$ bovine serum albumin (BSA). BSA enhances $\mathrm{AHH}$ activity $|27|$ and gives a better linear relationship between nuclear or microsomal protein concentration and $\mathrm{AHH}$ activity (data not shown). $1 \mathrm{ml}$ of adjusted nuclear or microsomal suspension in assay buffer was added and the flasks were preincubated for $5 \mathrm{~min}$ at $37^{\circ}$ in a Gallenkamp shaking incubator at $80 \mathrm{rev} / \mathrm{min}$ with an amplitude of $10 \mathrm{~mm}$. The reaction was started by the addition of $50 \mu \mathrm{l}$ of an $808 \mu \mathrm{g} / \mathrm{ml}$ BP solution in acetone. Concentrations at starting time in the $2 \mathrm{ml}$ assay medium were: 1 mM NADP, $5 \mathrm{mM}$ glucose-6-phosphate, 2 units $/ \mathrm{ml}$ glucose-6-phosphate dehydrogenase, $1 \mathrm{mg} / \mathrm{ml} \mathrm{BSA}$. $80 \mu \mathrm{M}$ BP, $2.5 \%$ acetone and 16()$-240 \mu \mathrm{g}$ of microsomal protein or $300-800 \mu \mathrm{g}$ of nuclear protein. 0.5 $\mathrm{ml}$ of the incubation mixture was taken at exactly $3 \mathrm{~min}$ and $6 \mathrm{~min}$ after the addition of $\mathrm{BP}$ and given into a tube with screw cap and teflon lining in ice. containing $0.4 \mathrm{ml}$ of acetone and $0.1 \mathrm{ml}$ of $1 \mathrm{M} \mathrm{HCl}$. $2 \mathrm{ml}$ of hexane were added. the tube was warmed up to $37^{\circ}$ and then, at ambient temperature. vigorously shaken for $10 \mathrm{~min}$. The addition of $\mathrm{HCl}$ to the solution prior to the first extraction step enhances 


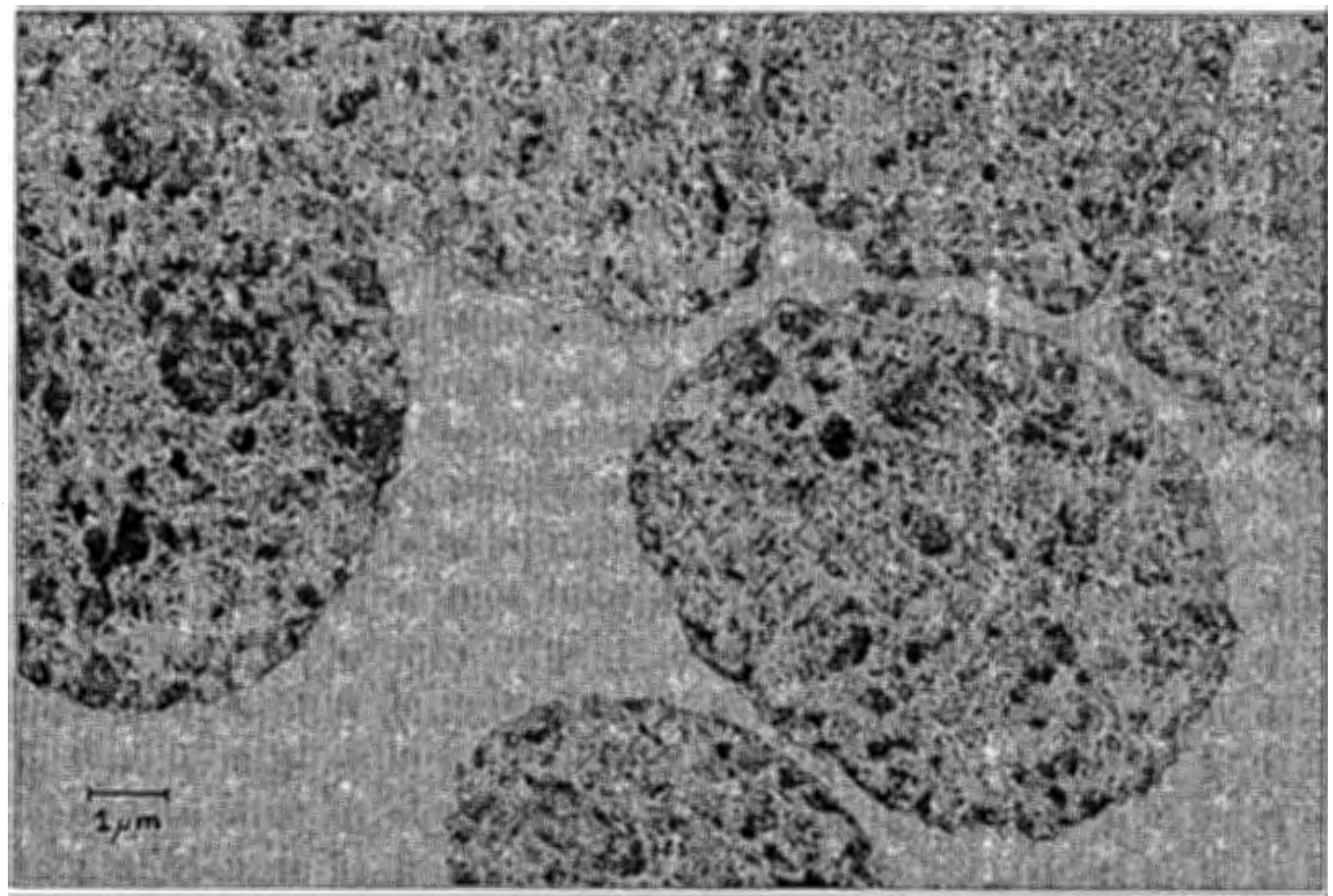

Fig. 1. Electron micrograph of isolated rat liver nuclei. They were fixed in glutaraldehyde, postfixed in osmium tetroxide. stained with lead and viewed in a Philips 200 electron microscope.

the yield of fluorescence to $127 \%$. This was also seen with synthetic 3-OH-BP after incubation in a complete assay medium but without the addition of NADP (to $118 \%$ ). $1 \mathrm{ml}$ of the organic phase was vigorously shaken for $10 \mathrm{~min}$ at room temperature with $3.5 \mathrm{ml}$ of $1 \mathrm{M} \mathrm{NaOH}$. The fluorescence of the $\mathrm{NaOH}$ phase was measured immediately in a Perkin Elmer 203 fluorescence spectrophotometer having a band pass of $10 \mathrm{~nm}$ at $396 \mathrm{~nm}$ (excitation) and 522 $\mathrm{nm}$ (emission). A quinine sulphate solution $(1 \mu \mathrm{g} / \mathrm{ml}$ in $50 \mathrm{mM} \mathrm{H}_{2} \mathrm{SO}_{4}$ ) was used as a fluorescent standard to calibrate the fluorometer. Standard solutions of synthetic 3-OH-BP in $1 \mathrm{M} \mathrm{NaOH}$ were used to check the accuracy of the fluorometer.

Protein measurements were made in duplicate according to Lowry et al. [28] with the modification that the protein solutions were made $0.1 \%$ in sodium dodecyl sulphate (SDS).

The AHH activity of the nuclear and microsomal fraction was determined in duplicate for each individual animal and the linearity with time was checked. Results giving a non-linear relationship or differing more than $10 \%$ from each other were rejected. Four to 12 animals were used for each determination.

\section{RESULTS}

The $\mathrm{AHH}$ activity was not changed by treating control animals with oil alone and was measured to

* One AHH unit is expressed as the amount of enzyme catalyzing the formation of alkali-extractable products causing fluorescence equivalent to that of one picomole of synthetic $3-\mathrm{OH}-\mathrm{BP}$ in $1 \mathrm{~min} / \mathrm{mg}$ protein. be $39.7 \pm 12.6$ AHH units* in nuclei (see Fig. 1 for their purity) and $2073 \pm 588$ AHH units in microsomes (mean \pm S.D.) for 48 animals. There was no variation between the control groups from the different sets of experiments either. These activities correlate well with the ones found by Jernström et al. [14], but are higher than those reported by others $(8,9,15,16,17,19]$. The discrepancy could be due not only to the use of different strains and animal care, but also to the experimental conditions of the AHH assay: The yield of fluorescent metabolites is proportional to the enzyme concentration in a low range only and only for a short incubation time.

The induction of $\mathrm{AHH}$ activity by the different chemicals is shown in Figs. 2 and 3 and is expressed relative to the control activity given above.

$M C$ induces both the nuclear and microsomal activity. In the beginning, the extent of $\mathrm{AHH}$ induction is significantly higher in the nuclear fraction, which is in agreement with observations by other authors $[9,14,16,17]$. After prolongedadministration, however, the nuclear activity is reduced to an induction rate similar to the one found in the microsomes.

TCDD gives rise to a similar time course of $\mathrm{AHH}$ induction except that after I day the nuclear $\mathrm{AHH}$ is induced less than the microsomal activity.

$B A$ causes a generally lesser induction but a similar time course.

As judged from spectroscopic evidence, these three chemicals are classified as cytochrome P448 inducers with MC as model compound (29) and their connexion is well reflected by the similar induction pattern. 

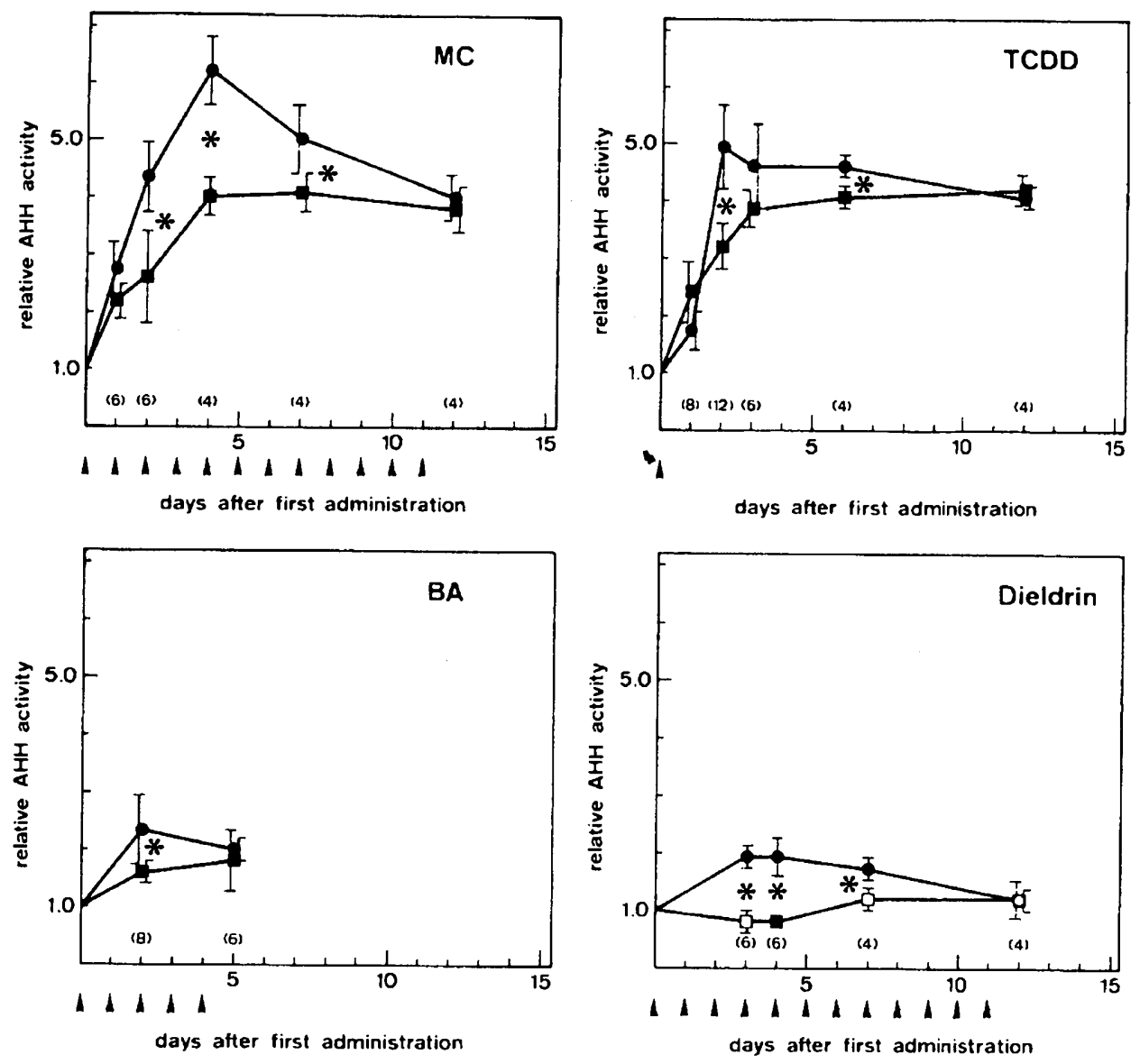

Fig. 2. Induction of aryl hydrocarbon hydroxylase $(\mathrm{AHH})$ in male rat liver nuclei $(\mathrm{O}, \bullet)$ and microsomes $(\square, \square)$ as a function of time after treatment with 3-methylcholanthrene (MC, $20 \mathrm{mg} / \mathrm{kg}), 2,3,7,8$ tetrachloro-dibenzo-p-dioxin (TCDD, $0.01 \mathrm{mg} / \mathrm{kg}$ ), benz $[a]$ anthracene (BA, $20 \mathrm{mg} / \mathrm{kg}$ ), and dieldrin (20 $\mathrm{mg} / \mathrm{kg}$ ). The $\mathrm{AHH}$ activity at day zero was set to 1.0 each for nuclei and microsomes. Each point represents the mean $\pm S$.D. (if larger than \pm 0.1 ) from the number of animals indicated in brackets. Intraperitoneal injections in corn oil are represented by arrows. Full symbols, $\bullet$ a: Significantly different from control $(P \leqslant 0.05)$ : *: significantly different induction in nuclei and microsomes $(P \leqslant 0.05$. students ' $t$ ' test).

PB only slightly induced the nuclear AHH activity, whereas the microsomal activity increased twice the control activity. These observations are similar to those reported by others $[9,17]$.

$D D T$ and $H C B$ show only slight induction of the two activities.

These three substances are members of the group of cytochrome P450 inducers, specified by PB [29].

Dieldrin causes no significant induction of the microsomal $\mathrm{AHH}$ after prolonged action. whereas the nuclear $\mathrm{AHH}$ is induced to a twofold activity after 3 and 4 days, and slowly decreases to the microsomal induction value after prolonged administration. The time course of the nuclear $\mathrm{AHH}$ activity resembles that of BA. i.e. that of a P448 inducer. On the other hand, the microsomal activity behaves much like the one after PB treatment, i.e. a P450 inducer. Dieldrin therefore seems not to belong to one or the other group of inducers but has some feature in common with both.

\section{DISCUSSION}

The data presented show that long-term treatment results in an equal relative induction of the $\mathrm{AHH}$ activity in microsomes and nuclei and that only the absolute value of the induction is dependent on the inducer used. This finding can be explained by postulating that the $\mathrm{AHH}$ activity in microsomes and nuclei is synthesized and regulated by the same control system or that there is a flow of $\mathrm{AHH}$ activity between the two compartments. This could explain the equilibrium found after a long time but does not take into account the observed differences in the time course of nuclear and microsomal AHH induction by different inducers.

In the first few days of treatment with compounds of the group of cytochrome P448 inducers (MC, TCDD, BA) the AHH activity is enhanced more in the nucleus than in the microsomal fraction. With $\mathrm{PB}$, a cytochrome $\mathrm{P} 450$ inducer, the induction in the microsomal fraction is higher than in the nucleus which does not respond at all to the treatment until day 8 . DDT does not show any difference between nuclear and microsomal induction at our time point. and the small difference found with HCB would probably disappear after a longer period of time. In order to explain all these different time courses of the $\mathrm{AHH}$ induction time-dependent secondary influences must be included: This could be a variability of the induction with regards to the site of synthesis. a change in the degradation rates of the 


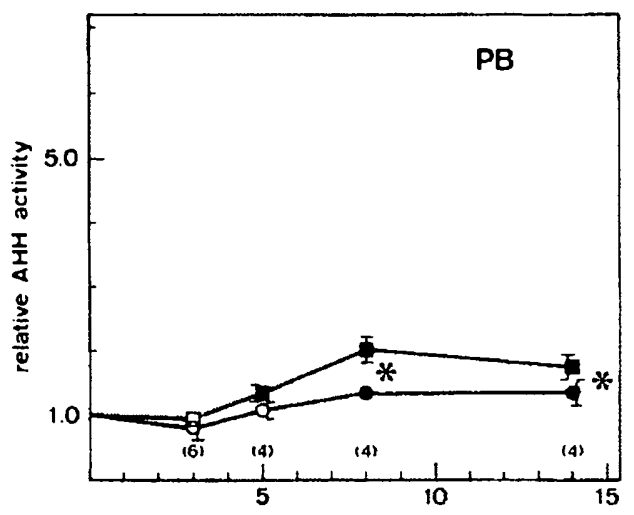

days after first administration

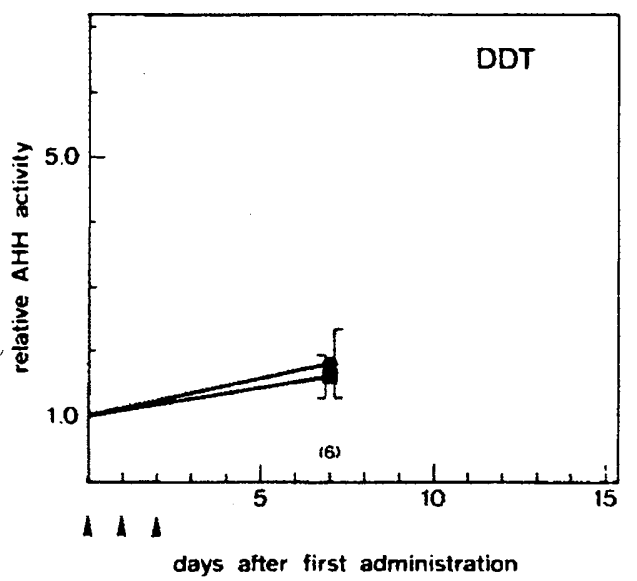

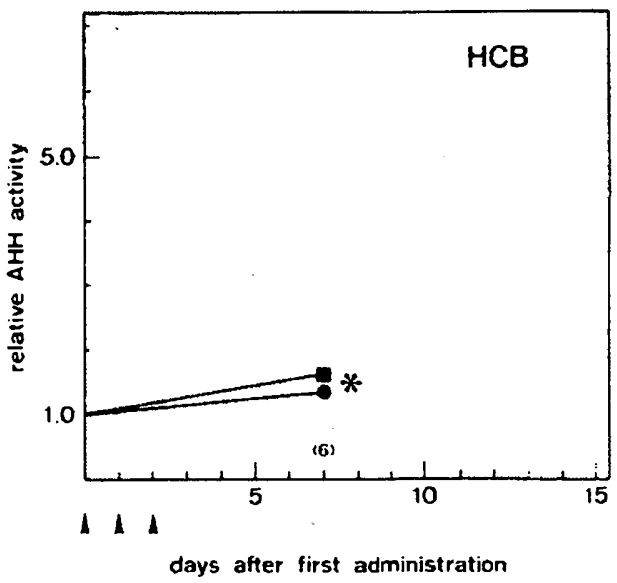

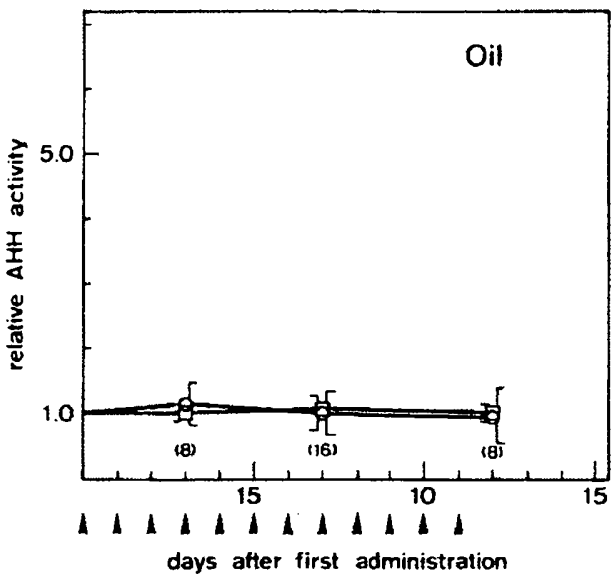

Fig. 3. Induction of $\mathrm{AHH}$ in male rat liver nuclei and microsomes as a function of time after treatment with phenobarbital (PB, given continuously in the drinking water at $1 \mathrm{~g} / \mathrm{l}$ ), hexachlorobenzene (HCB. $100 \mathrm{mg} / \mathrm{kg}$ ), 1,1,1-trichloro-2,2-bis(p-chlorophenyl)ethane (DDT, $30 \mathrm{mg} / \mathrm{kg}$ ) and corn oil $(2 \mathrm{ml} / \mathrm{kg})$. See legend to Fig. 2 for explanations.

AHH activities, or a change of the inter-membrane flow.

On the basis of our current knowledge we cannot favour any of these assumptions and more work has to be performed to elucidate the inherent mechanisms.

The different relative induction of the $\mathrm{AHH}$ activity in microsomes and nuclei obtained at different times with various inducers now allows us to determine the role of the two compartments in the extent of binding of PAH to DNA in vivo. Such investigations are in progress.

\section{REFERENCES}

1. D. W. Nebert and H. V. Gelboin, J. biol. Chem. 243, 6242 (1968).

2. A. H. Conney, E. C. Miller and J. A. Miller, J. biol. Chem. 228, 753 (1957).

3. A. H. Conney, Pharmac. Rev. 19, 317 (1967).

4. H. V. Gelboin, N. Kinoshita and F. J. Wiebel, Fedn Proc. 31, 1298 (1972).

5. P. Sims, Biochem. Pharmac. 16, 613 (1967).

6. P. Sims, P. L. Grover, A. Swaisland, K. Pal and A. Hewer, Nature, Lond. 252, 326 (1974).

7. P. Sims, IARC Scientific Publ. 12, 211 (1976).

8. C. W. Mehard and L. Packer. Bioenergetics 6, 151 (1974).
9. A. S. Khandwala and C. B. Kasper. Biochem. biophys. Res. Commun. 54, 1241 (1973)

10. H. V. Gelboin. Cancer Res. 29, 1272 (1969).

11. P. L. Grover and P. Sims, Biochem. J. 110, 159(1968).

12. H. W. S. King. M. H. Thompson and P. Brookes, Cancer Res. 34, 1263 (1975).

13. M. H. Thompson, H. W. S. King, M. R. Osborne and P. Brookes, Int. J. Cancer 17, 270 (1976).

14. B. Jernström, H. Vadi and S. Orrenius, Cancer Res. 36, 4107 (1976).

15. E. G. Rogan and E. Cavalieri. Biochem. biophys. Res. Commun. 58, 1119 (1974)

16. K. Alexandrov, P. Brookes, H. W. S. King. M. R. Osborne and M. H. Thompson, Chem.-Biol. Interact. 12, 269 (1976).

17. E. G. Rogan, P. Mailander and E. Cavalieri. Proc. Natn. Acad. Sci. U.S.A. 73, 457 (1976).

18. J. M. Pezzuto, M. A. Lea and C. S. Yang. Proceedings of the American Association for Cancer Research 18, 214 (1977), Abs. 855.

19. J. Vaught and E. Bresnick, Biochem. biophys. Res. Commun. 69, 587 (1976)

20. P. Brookes and P. D. Lawley, Nature. Lond. 4934,781 (1964).

21. S. G. Buty, S. Thompson and T. J. Slaga, Bicichem. biophys. Res. Commun. 70, 1102 (1976).

22. D. N. Wheatley, Br. J. Cancer 22, 787 (1968).

23. L. W. Wattenberg and J. L. Leong. Cancer Res. 30, 1922 (1970).

24. T. J. Slaga and R. K. Boutwell, Cancer Res. 37, 128 (1977). 
25. R. Berezney, 1. K. Macaulay and F. L.. Crane, J. hiol. Chem. 17, 5549 (1972).

26. J. B. Schenkman and D. I.. Cinti, L.if('Sii. 11, 247 (1972).

27. A. P. Alvares, G. Schilling. A. Garbut and R. Kunt\%man. Bioche'm. Phormac. 19. 1449 (1970).
28 O. H. Lowry. N. J. Rosebrough. A. L. Farr and R. J. Randall, J. biol. Chem. 193, 265 (1951).

29. P. E. Thomas. A. Y. H. L.u. D. Ryan. S. B. West, J. Kawalek and W. L.evin. J. hiol. Chem. 251, 1385 (1976). 